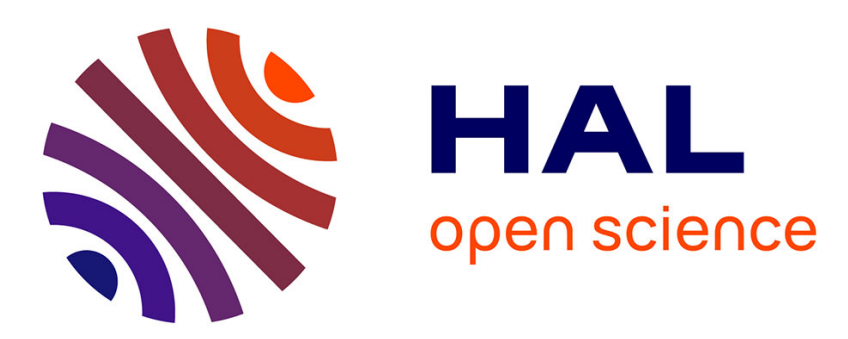

\title{
Multifunctionalization of cellulose microfibrils through a cascade pathway entailing the sustainable Passerini Multi-Component reaction
}

Asja Pettignano, Julien Leguy, Laurent Heux, Bruno Jean, Aurelia Charlot, Etienne Fleury

\section{To cite this version:}

Asja Pettignano, Julien Leguy, Laurent Heux, Bruno Jean, Aurelia Charlot, et al.. Multifunctionalization of cellulose microfibrils through a cascade pathway entailing the sustainable Passerini MultiComponent reaction. Green Chemistry, 2020, 22 (20), pp.7059-7069. 10.1039/D0GC02532A . hal02956163

\section{HAL Id: hal-02956163 \\ https://hal.science/hal-02956163}

Submitted on 13 Nov 2020

HAL is a multi-disciplinary open access archive for the deposit and dissemination of scientific research documents, whether they are published or not. The documents may come from teaching and research institutions in France or abroad, or from public or private research centers.
L'archive ouverte pluridisciplinaire HAL, est destinée au dépôt et à la diffusion de documents scientifiques de niveau recherche, publiés ou non, émanant des établissements d'enseignement et de recherche français ou étrangers, des laboratoires publics ou privés. 


\section{Multifunctionalization of cellulose microfibrils through a cascade pathway entailing the sustainable Passerini Multi-Component reaction}

Accepted 00th January 20xx DOI: $10.1039 / \times 0 \times x 00000 x$

\begin{abstract}
Asja Pettignano ${ }^{a}$, Julien Leguy ${ }^{b}$, Laurent Heux ${ }^{b}$, Bruno Jean $^{b}$, Aurélia Charlot $^{a}{ }^{*}$, Etienne Fleury ${ }^{a}$ *
Through a cascade of chemical derivatizations involving the green Passerini three-component reaction (P-3CR), we describe herein the multifunctionnalization of cellulose microfibrils (MFC) previously subjected to a periodate oxidation step. Not only do MFC constitute a remarkably attractive cellulose substrate from industrial and fundamental standpoints, but their periodate oxidation increases their reactivity while keeping their unique attributes. The Passerini reaction allowed for the successful grafting of two judiciously chosen chemical precursors in aqueous one-pot heterogeneous conditions, thus leading to the generation of dually modified (both functional and reactive) MFCs. Namely, as a proof of concept of this strategy, a tert-butyl isocyanide and a carboxylic acid, the latter bearing either an alkyne or a methacrylate function, were reacted with the aldehyde moieties present at the surface of periodate oxidized cellulose (POC). A thorough characterization evidenced the success of the double functionnalization, provided the degrees of substitution (DS) and allowed for elucidating the impact of structural (i.e. degree of oxidation of POC, nature of the acid partner) and experimental (i.e. amount of reagent) parameters on the P-3CR yield. Finally, the reactive Passerini-modified MFCs were conveniently post-derivatized by appealing aqueous coupling ligations. Specifically, MFC decorated with methacrylate functions were reacted with an amine through the aza-Michael reaction, while the propensity of alkyne-functionalized MFC to react through copper catalyzed Huisgen cycloaddition was demonstrated by grafting two different azides. This $P$ 3CR chemical strategy exhibiting good atom economy appears as a mild, versatile, and eco-friendly synthetic approach for the dual surface modification of MFCs. Furthermore, the facility to post-modify such reactive Passerini-modified MFC objects through various popular ligation reactions paves the way to the straightforward generation of a large panel of tailor-made MFC objects in a aqueous process, whose surface properties can be suitably adjusted to the targeted application by the right choice of the two precursors engaged in P-3CRs.
\end{abstract}

\section{Introduction}

The development of chemical derivatization routes conjugating sustainability and efficiency in mild conditions with a limited waste formation and allowing for bringing specific functionalities is a major and key challenge from both economical and societal points of view. In this regard, multicomponent reactions (MCRs), in which three or more raw precursors are chemically reacted in a one-pot manner to produce highly complex and diverse structures, represent a class of very attractive synthetic procedures. ${ }^{1}$ A striking

\footnotetext{
a. Université de Lyon, INSA LYON, Ingénierie des Matériaux Polymères IMP-UMR CNRS 5223 F 69621, Villeurbanne, France.

${ }^{b .}$ Université Grenoble Alpes, CERMAV, F-38000, Grenoble, France.

+ E-mail addresses and telephone numbers: A. Charlot: aurelia.charlot@insaIyon.fr, +33 (0)4 724363 38; E. Fleury: etienne.fleury@insa-lyon.fr, +33 (0)4 7243 63 35; Fax: $+33(0) 472438527$

Electronic Supplementary Information (ESI) available: SEM micrographs of unmodified and two exemplificative Passerini-modified POC, complementary FT-IR, Raman, TGA and NMR characterizations of the modified samples, spectral characterisation of blank samples. See DOI: $10.1039 / x 0 x x 00000 x$
}

example of MCR relies in the Passerini three-component reaction (P-3CR). First reported by Passerini in $1921,{ }^{2}$ this reaction assembles in one-pot a carboxylic acid with an isocyanide and an aldehyde, leading to a $\alpha$ acyloxycarboxamide link offering three functions in absence of any catalyst or coupling reagents and involving a minimum number of synthesis and purification steps. This Passerini coupling can be achieved in both organic solvent and water, generally requires mild conditions (i.e. $\mathrm{RT}$, short reaction times, mild $\mathrm{pH}$ ) and tolerates a wide variety of functional groups. ${ }^{3,4}$ Not only do these features qualify P-3CR as an advantageous environmentally friendly route, in its classical fields of application (i.e. organic synthesis and drug development), and in the polymer chemistry field, but also provides straightforward access to multifunctionalities. Even if its use in this domain still remains scarcely explored, Passerini reaction is progressively emerging as a powerful tool for the preparation of highly functionalized polymeric materials, for the synthesis of libraries of monomers and polymers as well as for the functionalization of a variety of synthetic and biobased macromolecules. ${ }^{5-7}$ In the perspective of sustainable 
development, the valorisation of natural polymers to generate novel functional materials, is highly valuable and appealing. ${ }^{7}$ Polysaccharides in particular represent good candidates to take part in Passerini reaction, thanks to their large abundance, their innocuousness, the presence of reactive functional groups on their backbone or the possibility of being suitably modified to bear the appropriated reactive functions. Despite these unique attributes, to the best of our knowledge, only five studies report the use of P-3CR to modify polysaccharides. For example, hyaluronic acid, naturally bearing carboxylic acid, and partially oxidized scleroglucan and pullulan, having both $-\mathrm{COOH}$ and aldehyde functions, have been successfully modified by P-3CR to produce chemically crosslinked hydrogels. ${ }^{8,9}$ Cellulose manifestly appears as a key and inescapable polysaccharide since it is not only the most abundant renewable resource on Earth but is also used in a plethora of applicative fields (paper, cosmetic, medical, textile, food, packaging, functional materials....). ${ }^{10}$ One of the distinctive features of cellulose is that it can be found under in its native crystalline state as traditional fibres or as nanocellulose (regrouping cellulose microfibrils, MFC, and cellulose nanocrystals, CNC) differing in their organisation state, degree of crystallinity, purity, dimensions and specific surface area etc., which dictate their utilizations. ${ }^{11-14}$ Alternatively, amorphous and potentially soluble cellulose derivatives (mainly ethers and esters) are commercially available and generally used as additives. Aiming at conferring improved or novel properties and subsequently enlarging their application field, numerous efforts have been devoted to the chemical modification of cellulose and its derivatives. ${ }^{15-17}$ In this framework, and given the dual functionalization offered by the Passerini reaction, this chemical strategy has been applied to carboxymethyl cellulose (CMC) in aqueous medium as described by our team, ${ }^{18}$ and to cellulose filter paper. ${ }^{19}$ In this last example, a succinylation reaction was first carried out to yield soluble derivatives amenable to P-3CR modification in DMSO. ${ }^{19}$ Among crystalline cellulosic substrates, MFCs present particularly appealing features. ${ }^{20}$ Indeed, they share common properties with CNCs such as lightweight character, abundant and renewable origin, high specific surface area or broad chemical modification ability but also exhibit specific characteristics such as high viscosity due to their very high aspect ratio and entanglements and ability to form homogeneous flexible films (while short aspect ratio CNCs rather form brittle films). Moreover, MFCs are economicallyviable biosourced particles since they are currently industrially produced at very large scales at a production cost well below that of CNCs. ${ }^{21} \mathrm{MFC}$ are also already integrated in commercial products (cosmetic, health and beauty, ink...) and can be used to prepare a large panel of materials in the domains of paper, paint and coatings, adhesives, composites, cement, oil and gas, films, etc, under various forms (suspension, foams, composites). ${ }^{22}$ All these assets demonstrate the widespread interest towards MFC objects, as remarkable cellulose substrate to be chemically modified. However, despite obvious advantages related to its various aforementioned green aspects and the major interest to introduce two functionalities (function, property, reactivity...) on a single chemical link, the modification of MFCs in heterogeneous conditions through $\mathrm{P}-3 \mathrm{CR}$ is still in its infancy. To our knowledge the only work on that topic was reported by Stenzel and co-workers in 2018 who grafted by P-3CR in heterogeneous aqueous conditions aldehyde-bearing thermoresponsive poly-( $\mathrm{N}$-isopropylacryl amide) chains and cyclohexyl isocyanide onto MFCs preliminary oxidized by the TEMPO method to introduce reactive carboxylic acid moieties. ${ }^{23}$ Besides already mentioned TEMPO oxidation and succinylation strategies, enabling the introduction of carboxylic acid groups, another way to provide Passerini-reactive functions to a cellulosic substrate is periodate oxidation. ${ }^{24-26}$ Periodate oxidation is known to selectively cleave bonds between vicinal diols, present on the glucose repeating unit of cellulose between $\mathrm{C} 2$ and C3 positions, leading to the formation of two aldehyde functions. ${ }^{27,28}$ Besides, using periodate oxidized MFC with aldehyde functions instead of TEMPO oxidized one in P-3CR is particularly motivating, since a large library of commercially available carboxylic acids with various functionalities and reactivities are amenable to react. Moreover, contrary to the TEMPO strategy, it was shown that the periodate oxidation yields a two-phase core-shell product comprising a dialdehyde cellulose skin surrounding an intact but partially consumed native cellulose core, significantly enhancing the reactivity and accessibility of the aldehyde moieties present at the surface, and allowing to completely benefit from the inherent attributes of MFC linked to its crystalline nature and required for applications in the material field. ${ }^{29}$ Additionally, the periodate oxidation can lead to high degree of oxidation (DO from 0 up to 2, contrary to 0.3-0.4 with TEMPO oxidation which only acts on primary hydroxyl groups). ${ }^{27,28}$ This point combined with the peculiar core-shell structure of periodate oxidized cellulose (POC) offer a wide flexibility of postmodification and thus a fine control of the physical properties tuneable by the DO. Also, it is important to note that periodate is industrially manageable, since it can be recycled by costefficient, up-scalable and green approaches. ${ }^{30-32}$ Previously reported pathways for the modification of oxidized celluloses bearing aldehyde functions mostly include imination ${ }^{33,34}$ or reductive amination. ${ }^{35-40}$ However, most of these reactions present limitations from environmental standpoint (need of generally toxic reductive reagent, need of a large excess of reagents in non-aqueous media), ${ }^{34,35}$ and above all these chemical routes lead only to a single functionalization. Consequently, in the quest for derivatization routes of MFC object conjugating a green character, efficiency in heterogeneous medium, and the access of dually modified and multi-functional products, we report herein the first example of Passerini modification of periodate oxidized MFC, stemming from the chemical coupling of aldehyde functions anchored onto the surface of periodate oxidized cellulose microfibrils with tert-butyl isocyanide and different carboxylic acids. Thus, in the first part of this article, we describe P-3CR modifications from the use of carboxylic acids bearing reactive functions in order to yield Passerini-modified products prone to be straightforwardly functionalized through popular and 
attractive synthetic reactions. In order to demonstrate the attractiveness of the approach for a large scientific community and the potential of such a dual Passerini modification, we have turned towards judiciously chosen acids: 4-pentynoic acid and methacrylic acid, respectively reactive in the coppercatalysed Huisgen cycloaddition and aza-Michael reaction and both couplings being achievable in mild aqueous conditions. The impact of the nature of the reagents and the experimental conditions on the Passerini process is reported, and the derivatizations of the resulting Passerini-functionalized $P O C$ (bearing alkyne or alkene functions) through aza-Michael, and CuAAc reactions were examined by Raman spectroscopy and fluorescence microscopy.

\section{Results and discussion}

Periodate oxidation of microfibrillated cellulose (MFC), leading to the corresponding $\mathrm{POC}$, consists in the opening the glucosyl ring and in the subsequent formation of two aldehyde groups (Scheme 1, 2). This controlled oxidation step of cellulose microfibrils allows for the decoration of MFCs with aldehyde moieties, suitable to be engaged into P-3CR, with a large panel of carboxylic acids differing in reactivity or/and functionality and available at large commercial scale. This ligation consists in combining the previously formed aldehyde groups with tertbutyl isocyanide ( $t B)$ and a carboxylic acid, to form a $\alpha$-acyloxycarboxamide group (Scheme 1,3 ). This synthetic route presents the advantages of being efficiently carried out in one-pot aqueous conditions without the use of catalyst or coupling reagents. In the present study, not only we do aim at verifying the applicability of the reaction to MFCs with reactants bearing different functions, but we aspire to demonstrate the huge potential of designing MFCs decorated with multiple functions in an experimental route conjugating sustainability and simplicity of implementation. Herein, we selected a hydrophobic isocyanide and we combined it with carboxylic acids potentially reactive in a further derivatization step, namely methacrylic acid (MA) or 4-pentynoic acid (Pent). Note that in a sustainable development approach, methacrylic acid can be renewably available. ${ }^{41}$ Concerning 4-pentynoic acid, it is defined as a product with relatively poor toxicity and, as recently described, it can interestingly be produced from oxidation of a mixture of products exhibiting no toxicity neither for the health, nor for the environment. ${ }^{42}$ The use of such MA and Pent reactants paves the way to decorate the MFC surface with methacrylate and alkyne functions, respectively reactive in various attractive ligations (radical or aza-Mickael reactions, click coupling, hydrosylilations) combining industrial and sustainable interests. Thus, P-3CR was achieved with two POCs with two different degrees of oxidation ( $D O=0.34$ or 0.77 , corresponding to the ratio of aldehyde groups to the total number of anhydroglucose units, $A G U)$. Such POC derivatives were obtained from a wellestablished procedure, and the DO is finely controlled by the right choice of periodate to AGU ratio and/or the appropriated reaction time. ${ }^{29}$ Thus, the effect of the oxidation extent of POC on the Passerini reactivity has been examined. For sake of clarity, the modified POCs will be referred to as: $\mathrm{POC}_{\mathrm{DO}}-\mathrm{Acid}-\mathrm{B}$ and the abbreviations used to appoint the different acids are reported in Table 1. P-3CR was performed by simply adding the selected acid followed by tert-butyl isocyanide to a dispersion of POC in distilled water, and by stirring the obtained mixture at RT for $18 \mathrm{~h}$. At the end of the reaction, the products were repeatedly washed with distilled water, followed by centrifugation, freeze-dried and recovered in moderate to high mass yields (Table 1, 61-87 \%). At equal amounts of reagents used in the reaction (up to 3 eq. in acid and isocyanide, e.g. Table 1, Entries 3,4 vs Entries 5,6, and Entries 10,11 vs Entries 12,13), POCs with higher DO generally led to slightly lower yields. This behaviour probably arises from the presence of shorter cellulose chains generated during the periodate oxidation, more easily removed during the work-up step, with increasing DO. ${ }^{43}$ After the reaction, the recovered modified MFC samples did not show any morphological alterations, as attested by comparisons of the SEM images of unmodified POC and of two corresponding modified products, differing by the presence of a pentynoic or of a methacrylate function (Fig. S1).
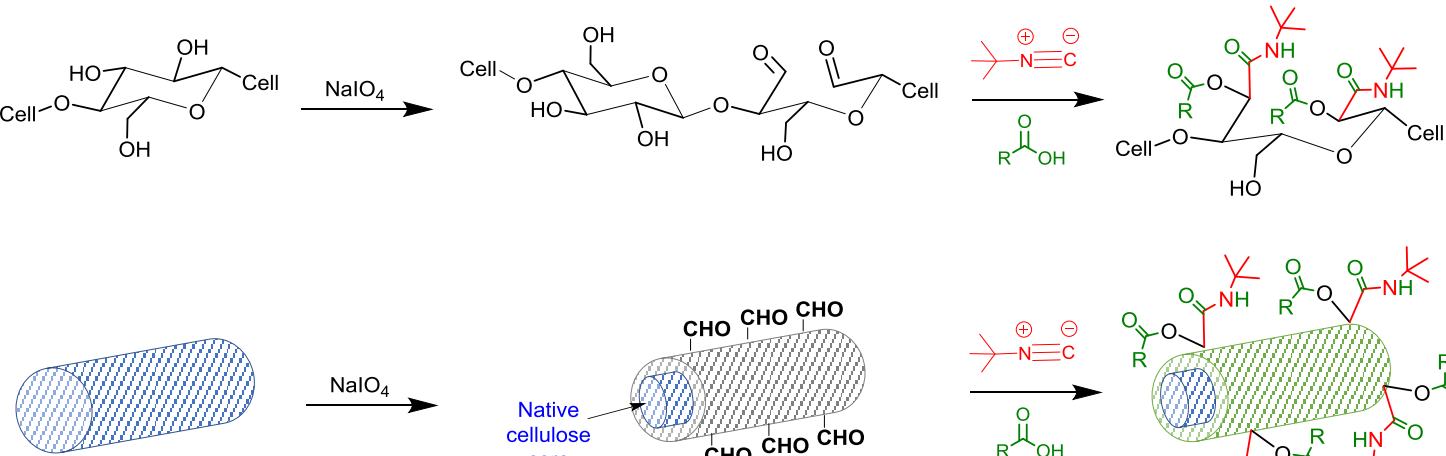

MFC

1

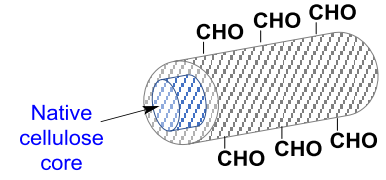

POC
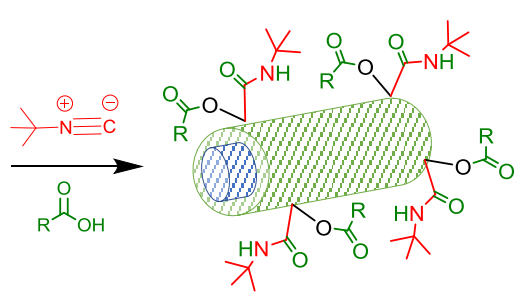

Passerini modified POC

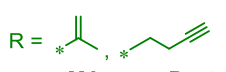

MA Pent

Scheme 1. Reaction scheme of periodate oxidation of MFC and subsequent modification by Passerini-3CR. 
Table 1. Scope of the Passerini-3CR between POC (1), tert-butyl isocyanide (2) and different carboxylic acids (3).

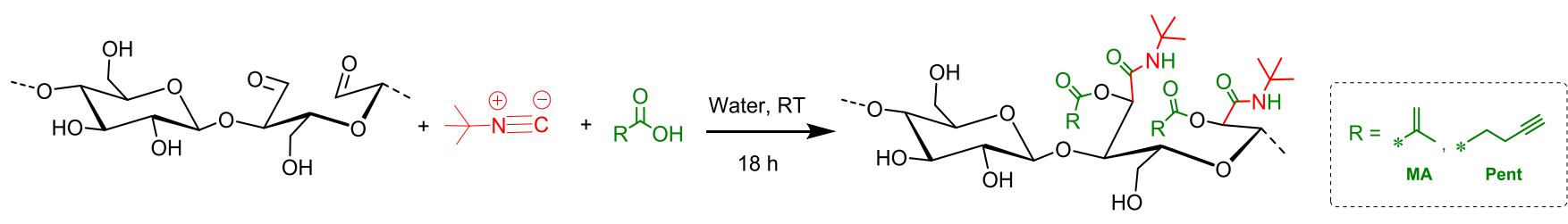

2

3

4

\begin{tabular}{|c|c|c|c|c|c|c|c|}
\hline Entry & Sample ${ }^{a}$ & DO POC & $\mathbf{R}$ & Eq. $R^{b}$ & $\begin{array}{l}E q . \\
t B^{b}\end{array}$ & $\begin{array}{c}\text { Mass } \\
\text { Yield (\%) }\end{array}$ & $D^{c}{ }^{c}$ \\
\hline 1 & \multirow{4}{*}{$\mathrm{POC}_{0.77}$-Pent- $t \mathrm{~B}$} & \multirow{4}{*}{0.77} & \multirow{4}{*}{ 4-pentynoic acid } & 0.5 & 0.5 & 80 & 0.06 \\
\hline 2 & & & & 1 & 1 & 76 & 0.08 \\
\hline 3 & & & & 1.5 & 1.5 & 67 & 0.10 \\
\hline 4 & & & & 3 & 3 & 74 & 0.10 \\
\hline 5 & \multirow{3}{*}{ POC $_{0.34}$-Pent- $t \mathrm{~B}$} & \multirow{3}{*}{0.34} & \multirow{3}{*}{ 4-pentynoic acid } & 1.5 & 1.5 & 87 & 0.04 \\
\hline 6 & & & & 3 & 3 & 85 & 0.05 \\
\hline 7 & & & & 6.8 & 6.8 & 65 & 0.06 \\
\hline 8 & \multirow{4}{*}{$\mathrm{POC}_{0.77}-\mathrm{MA}-\mathrm{tB}$} & \multirow{4}{*}{0.77} & \multirow{4}{*}{ Methacrylic acid } & 0.5 & 0.5 & 77 & 0.06 \\
\hline 9 & & & & 1 & 1 & 76 & 0.09 \\
\hline 10 & & & & 1.5 & 1.5 & 63 & 0.10 \\
\hline 11 & & & & 3 & 3 & 70 & 0.11 \\
\hline 12 & \multirow{3}{*}{$\mathrm{POC}_{0.34}-\mathrm{MA}-\mathrm{tB}$} & \multirow{3}{*}{0.34} & \multirow{3}{*}{ Methacrylic acid } & 1.5 & 1.5 & 86 & 0.04 \\
\hline 13 & & & & 3 & 3 & 81 & 0.05 \\
\hline 14 & & & & 6.8 & 6.8 & 61 & 0.06 \\
\hline
\end{tabular}

${ }^{a}$ Reaction conditions: POC $1.5 \% \mathrm{w} / \mathrm{v}$ in distilled water, ratio carboxylic acid/isocyanide $=1: 1,18 \mathrm{~h}$ and RT; ${ }^{\mathrm{b}}$ Eq. of reagents with respect to available - $\mathrm{CHO}$ groups; ${ }^{\mathrm{C}} \mathrm{DS}$ calculated by CP-MAS ${ }^{13} \mathrm{C}$ NMR of modified POCs, calculated as the mean value obtained by integrating four different signals. The uncertainty of the DS calculation method, evaluated in terms of relative standard deviation, was estimated as $<10 \%$.

The success of P-3CR was qualitatively and quantitatively characterized from the use of a series of analytical techniques. Firstly, ATR-IR and Raman spectroscopies were used, and Fig. 1 illustrates the comparison between the spectra of unmodified POC, POC $_{0.77}$-Pent- $t \mathrm{~B}$ (Table 1, Entry 4) and $\mathrm{POC}_{0.77}-\mathrm{MA}-t \mathrm{~B}$ (Table 1, Entry 11), chosen as examples to prove the achievement of the P-3CR. The ATR-IR spectra of POC (Fig. 1A) is characterized by the presence of a weak aldehyde signal at around $1740 \mathrm{~cm}^{-1}$, whose low intensity is due to the wellknown formation of hydrated species, hemiacetals and hemialdols. ${ }^{44}$ When comparing the spectrum of POC with those of Passerini-modified products (Fig. 1, 1A, 1B and 1C), the weak aldehyde adsorption peak is replaced by a more pronounced one, corresponding to the formation of the ester bond $\left(\approx 1740 \mathrm{~cm}^{-1}\right)$. Moreover, the presence of two new intense bands can be observed at around $1660 \mathrm{~cm}^{-1}$ and 1540 $\mathrm{cm}^{-1}$, corresponding respectively to the amide I and amide II signals, $^{45}$ qualitatively but unambiguously attesting the successful formation of the $\alpha$-acyloxycarboxamide function through Passerini reaction. Concerning Raman analysis, the spectrum of POC (Fig. 1, 2A) only shows signals related to the cellulosic backbone, while the Passerini-modified products (Fig. 1, 2B and 2C) are both characterized by the presence of the ester bond $\left(\approx 1740 \mathrm{~cm}^{-1}\right)$ and of the respective carboxylic acids: $\mathrm{POC}_{0.77}$-Pent- $t \mathrm{~B}$ exhibiting the signature of the alkyne moieties, at $2120 \mathrm{~cm}^{-1}$, and $\mathrm{POC}_{0.77}-\mathrm{MA}-\mathrm{t} \mathrm{B}$ displaying the alkene one, at $1635 \mathrm{~cm}^{-1}$. 
1)

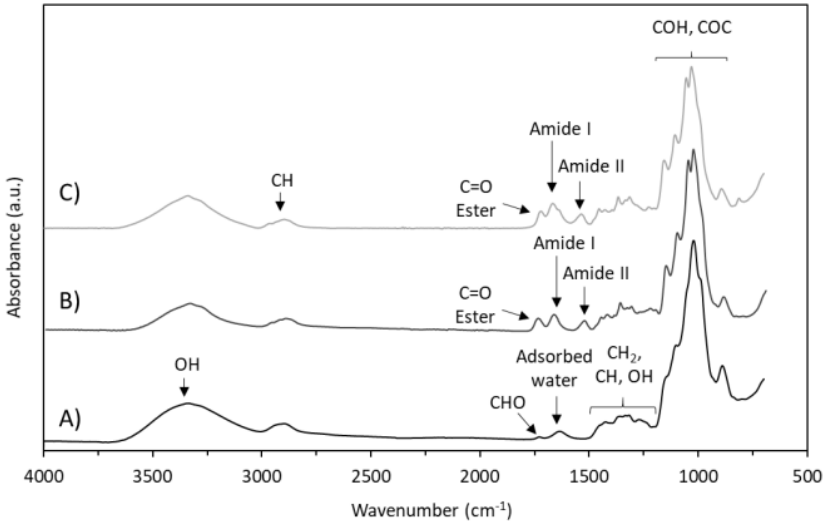

2)

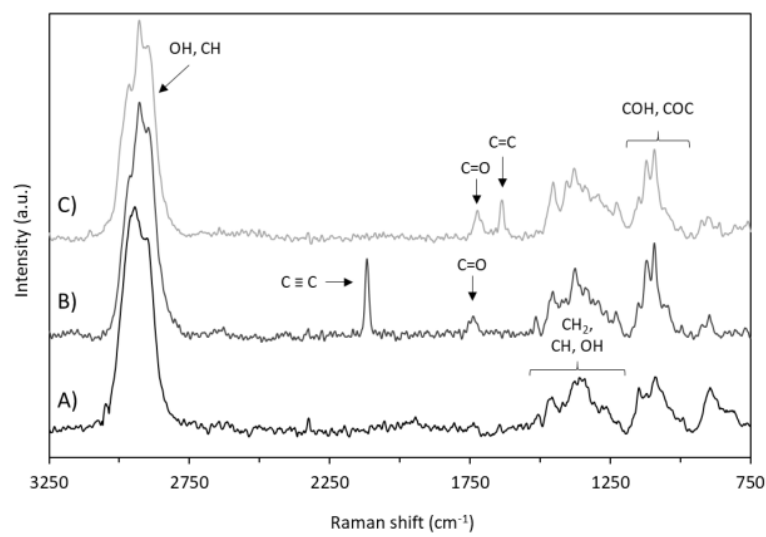

Fig. 1. ATR-IR (1) and Raman (2) spectra of unmodified POC, DO = 0.77 (A, and $\mathrm{POC}_{0.77}$-MA-tB (Table 1, Entry 11) (C, $\longrightarrow$ ).

In order to exclude any adsorption of the reagents at the POC surface, control reactions were performed by mixing the POC and the chosen acid, in absence of isocyanide, and subjecting the mixture to the same reaction and work-up protocol employed for the Passerini modification. ATR-IR and Raman analyses were performed on the control samples and compared to unmodified POC (Fig. S2). No difference between the corresponding IR spectra can be detected, which confirms that no physisorption of the acid occurs onto the cellulosic objects. Additionnaly, through a topochemical mapping of the functionalized MFC surface, we intended to image the distribution of alkyne or alkene moieties by Raman microscopy. For this purpose, a Raman mapping was carried out on a surface of $1300 \times 800 \mu^{2}$ for two exemplificative modified POCs, from the intensity of the Raman alkyne response (Fig. 2A: $P O_{0.77}$-Pent- $t B$, Table 1, Entry 4) or alkene functions (Fig. 2B: $\mathrm{POC}_{0.77}-\mathrm{MA}-\mathrm{B}$, Table 1, Entry 11), after a normalization to a typical $\mathrm{C}-\mathrm{O}-\mathrm{C}$ band of cellulose backbone at
$1100 \mathrm{~cm}^{-1}$. Both images reveal the presence of the expected signals, proving again the successful completion of the Passerini modification. However, some disparities and fluctuations in terms of alkyne or alkene concentration (more highly and less modified regions in blue and yellow, respectively) emerge. Given the spatial resolution of the Raman imaging (around $10 \mu \mathrm{m}$ ), individual microfibrils cannot be distinguished, and these intensity gradients much probably stem from the Raman detection, which is interfered by the peculiar surface geometric features of the sample. Indeed, raw MFC are relatively polydisperse and can be found under aggregated objects, due their origin and their production process (mechanical), as observed by the SEM pictures (Fig. S1). Also, the preparation of the sample to be analysed implies a drying step, which can induce the formation of more or less collapsed zones. All these aspects contribute to generate a non-negligible roughness to the sample that disrupts the Raman response, and thus the intensity of the detected signal.
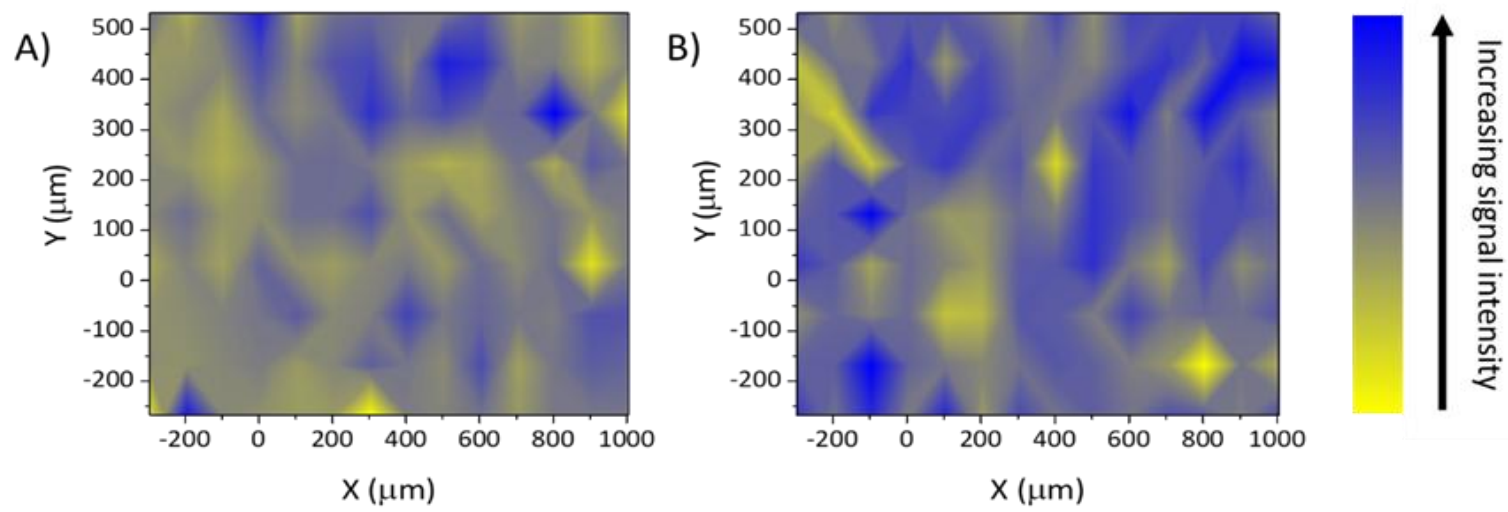

Fig. 2. Raman confocal micrograph of A) $P O C_{0.77}-$ Pent- $t$ B (Table 1, Entry 4), based on the alkyne band intensity at $2120 \mathrm{~cm}^{-1}$ and B) $\mathrm{POC}_{0.77}-\mathrm{MA}-\mathrm{tB}$ (Table 1, Entry 11), based on the alkene band intensity at $1635 \mathrm{~cm}^{-1}$, after normalization on cellulose backbone band at $1100 \mathrm{~cm}^{-1}$. 


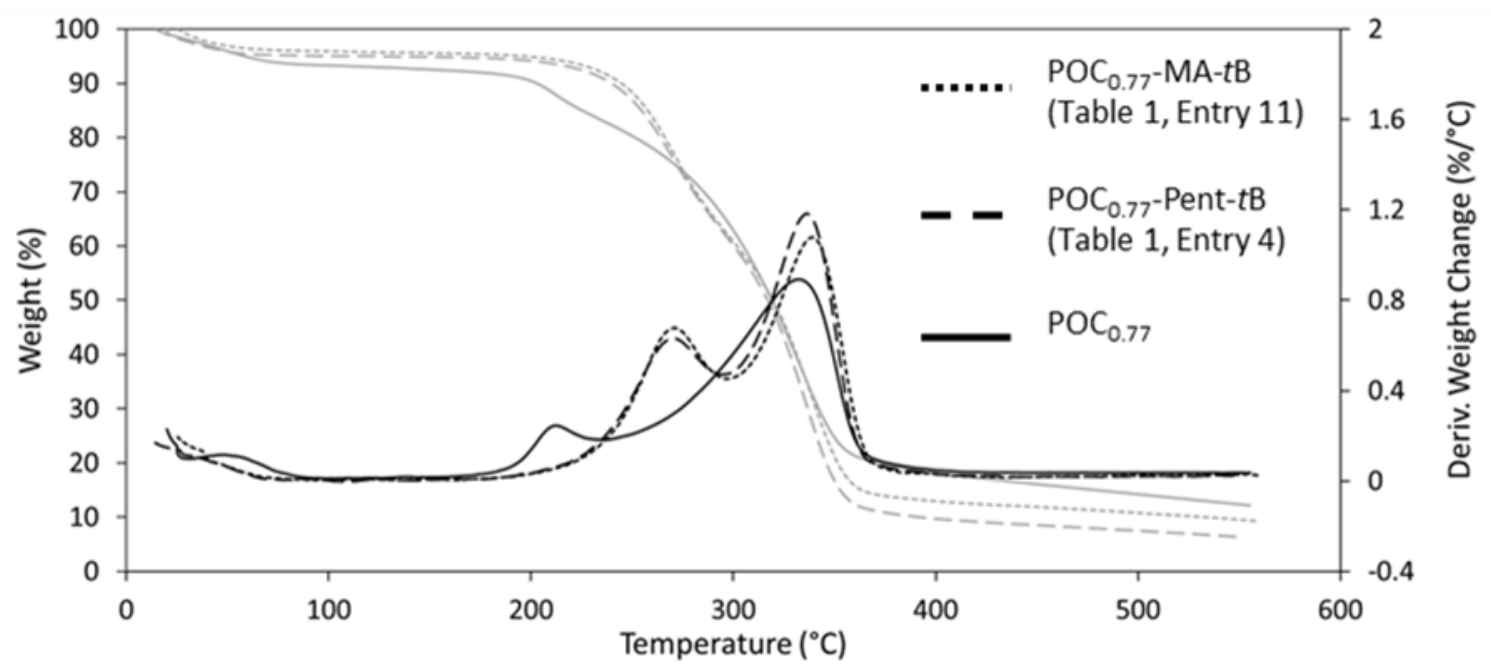

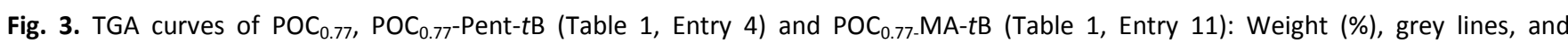
Derivative Weight Change $\left(\% /{ }^{\circ} \mathrm{C}\right)$, black lines.

Additionally, thermogravimetric analysis (TGA) of derivatized POCs shows an incontestable impact of the Passerini modification on the thermal behaviour, when comparing the thermograms of unmodified $P O C$ and of two typical functionalized products (Fig. 3), POC $_{0.77}$-Pent-tB (Table 1, Entry 4) and $P \mathrm{CC}_{0.77}-\mathrm{MA}-t \mathrm{~B}$ (Table 1, Entry 11). As described in the literature, ${ }^{33}$ the thermal decomposition of POC proceeds in two stages: $i$ ) an initial weight loss, centred around $210^{\circ} \mathrm{C}$ and increasing in intensity with increasing $\mathrm{DO}$, attributed to the degradation of the oxidized cellulose segments and, ii) the thermal degradation of the cellulosic core, reaching the maximum weight loss $\left(\mathrm{Td}_{\max }\right)$ around $330{ }^{\circ} \mathrm{C}$, characterized by a progressively smaller and wider signal profile with increasing DO. When compared to unmodified POC, Passerini products exhibit an unchanged $\mathrm{Td}_{\max }$ value, indicating that the cellulosic backbone is not affected by the chemical modification.
Similarly, the mass loss at $210^{\circ} \mathrm{C}$ disappears and is replaced by a more intense thermal degradation response around $270{ }^{\circ} \mathrm{C}$, which could be attributed to the decomposition of the covalently tethered moieties. Thus, ATG also proves the successful modification of oxidized MFC. Quantitative and qualitative information on the structure of the P-3CR modified derivatives were obtained by means of ${ }^{13} \mathrm{C} C P-M A S ~ N M R$ spectroscopy. Fig. 4 shows the spectra of $\mathrm{POC}_{0.77}$-Pent- $t \mathrm{~B}$ (Table 1, Entry 4) and $\mathrm{POC}_{0.77}-\mathrm{MA}-t \mathrm{~B}$ derivatives (Table 1, Entry 11), which will be taken as examples to discuss the NMR characterization. According to the available literature, ${ }^{29,37,38,46,47}$ signals corresponding to POC backbone can be typically identified in the region between 55 and 110 ppm. The absence of peaks in the carbonyl region (160-200 $\mathrm{ppm}$ ) has been ascribed to the absence of aldehyde functions in their free form, due to their tendency to recombine with

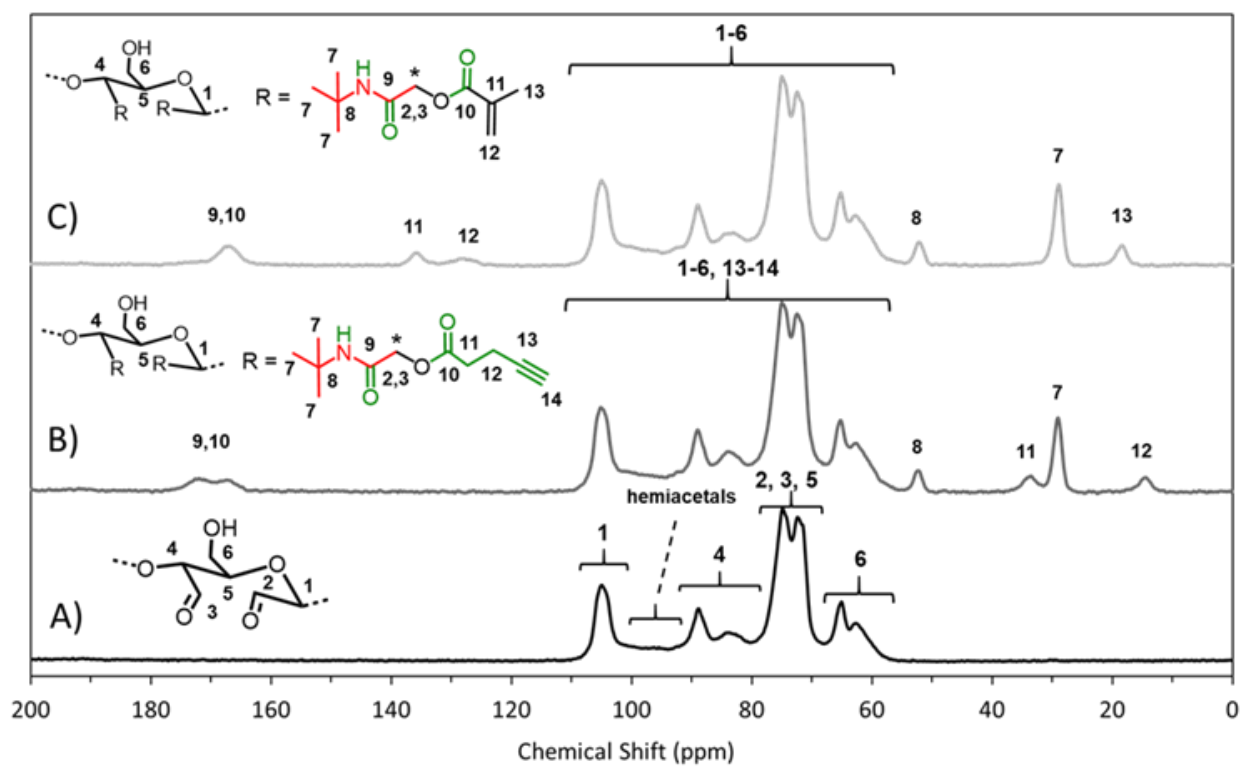

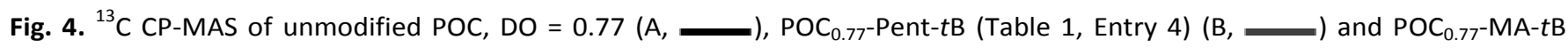
(Table 1, Entry 11) (C, _ $)$. 
neighbouring hydroxyl groups and to form hemiacetal moieties, which give rise to a broad signal in the 90-100 ppm region. As a result of the multicomponent reaction, new signals corresponding to the attached moieties can be identified, evidencing the efficiency of the chemical derivatization. Both modified POC samples display the presence of carbon signals attributed to the tert-butyl isocyanide (carbons 7 and 8 , at 30 and $52 \mathrm{ppm}$ respectively) and to the ester and amide carbonyls (carbons 9 and 10, 160$180 \mathrm{ppm}$ ) of the $\alpha$-acyloxycarboxamide chemical link. Furthermore, the NMR spectra were characterised either by the signal of the corresponding 4-pentynoic acid (carbons 11 and 12 , at 33 and $14 \mathrm{ppm}$, while carbons 13 and 14 overlap the POC region, spectrum B) and methacrylic acid (carbons 11 and 12 , between 120 and $140 \mathrm{ppm}$, and carbon 13, at $18 \mathrm{ppm}$, spectrum A). Note that the successful achievement of P-3CR for all samples gathered in Table 1 was consistently proved by ATR-IR, Raman and ${ }^{13} \mathrm{C}$ CP-MAS, as described in SI part (Fig. S3S14). ${ }^{13} \mathrm{C}$ CP-MAS was also exploited to determine the extent of the Passerini modification, quantified by the values of degree of substitution (DS), as detailed in the Experimental section. The DS values allowed us for shedding light on the effect of the used reagents, in terms of amounts and chemical structures, on the reaction outcome. The use of different carboxylic acids, while keeping similar reaction conditions does not lead to any significant difference (Table 1, Entries 1-4 vs 811 and entries 5-7 vs 12-14). Both 4-pentynoic and methacrylic acids seem to have similar reactivities in the P-3CR. In the same way, when POC with different DO values are used, a comparable reactivity could be observed. POC presenting a lower degree of oxidation value ( $D O=0.34$ vs 0.77 ), yields lower DS values when the same reaction conditions were applied (Table 1, Entries 3-4 vs 5-6 and entries 10-11 vs 12-13), related to a lower amount of aldehyde functions prone to react into P-3CR. Nevertheless, by normalising the obtained DS with the starting DO, it could be noticed that analogous grafting efficiencies (12-15\%) were reached. Finally, the possibility of tuning the DS by varying the amount of reagents was examined for each POC/acid couple. As expected, the reaction is favoured by the use of larger amounts of reactants, which generally leads to enhanced DS values. When increasing the equivalents of reagents from 0.5 to 1 and above, the increase of DS is less marked than envisioned. This seems to indicate that the Passerini modification extent might be controlled by the availability or accessibility of POC aldehyde functions. The surface of the oxidized MFC is decorated by a crown of aldehyde moieties (more or less thick, depending on the DO value), and the dual Passerini coupling with the first reagents at proximity leads to a relatively bulky acyloxycarboxamide chemical link, which can sterically hamper further reactions with neighbouring aldehyde functions. Nevertheless, if we compare the amount of grafted $\alpha$ acyloxycarboxamide moieties to the starting aldehyde functions, the grafting ratios obtained (0.10-0.18) are comparable to those previously reported by Sirviö and his group for the reductive amination of $P O C$ in presence of different alkyl amines $(0.08-0.23) .{ }^{36,40}$ Then, the possibility of employing alkyne and alkene functions for further suited

A)

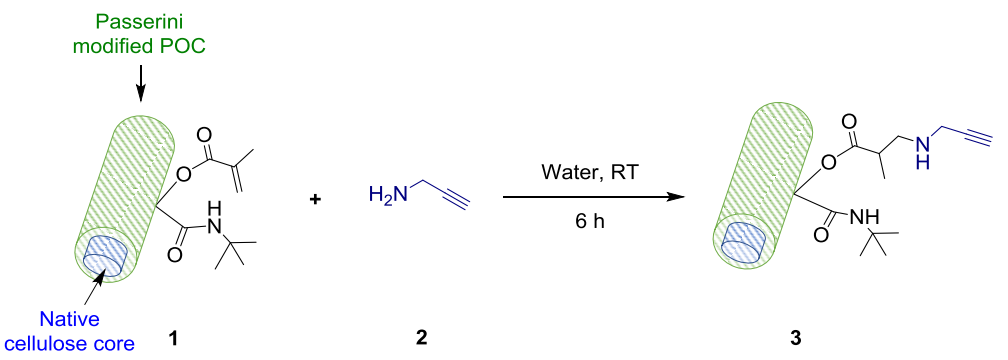

B)

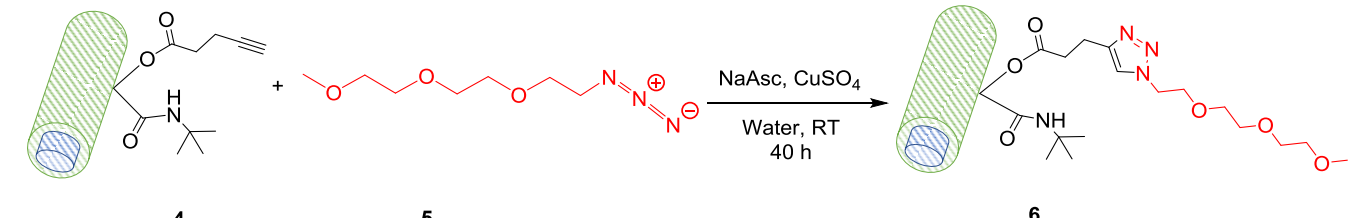

4

5

C)

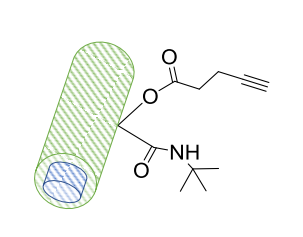

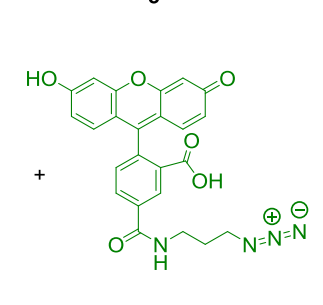

8

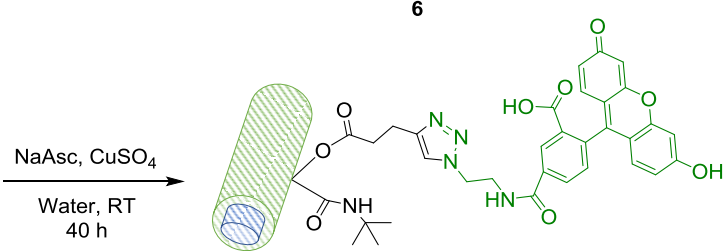

Scheme 2. Post-modification of Passerini POC derivatives by $A)$ aza-Michael reaction with propargylamine and $P O C_{0.77}-M A-t B$ (Table 1, Entry 11) to obtain $\mathrm{POC}_{0.77}$-Propargyl (3); B) Huisgen reaction with 1-Azido-2-(2-(2-methoxyethoxy)ethoxy)ethane (POC$\mathrm{N}_{3}$ ) and $\mathrm{POC}_{0.77}-\mathrm{P}-\mathrm{tB}$ (Table 1, Entry 4) to obtain $\mathrm{POC}_{0.77^{-}} \mathrm{POC}-\mathrm{MEE}(6) ; \mathrm{C}$ ) Huisgen reaction with 5-Fluorescein-Azide and POC ${ }_{0.34}{ }^{-}$ Pent-tB (Table 1, Entry 5) to obtain POC $_{0.34}$-Fluo (9). 
derivatization steps was investigated. Firstly, the reactivity of methacrylate-functionalized $\mathrm{POC},\left(\mathrm{POC}_{0.77}-\mathrm{M}-t \mathrm{~B}\right.$, Table 1, Entry 11) was assessed in the aza-Michael reaction with propargylamine (Scheme 2A). The success of the reaction was demonstrated by Raman spectroscopy ( $\mathrm{POC}_{0.77}$-Propargyl, Fig. $5 \mathrm{~A})$, which unambiguously shows the appearance of the alkyne signal $\left(2120 \mathrm{~cm}^{-1}\right)$ coming from the ligation with propargylamine. Similarly, alkyne-functionalised POC was subjected to the well-known copper-catalysed Huisgen cycloaddition reaction with two different azide-bearing molecules (Scheme 2, B and C). The reaction of $\mathrm{POC}_{0.77}-\mathrm{P}-\mathrm{t} \mathrm{B}$, (Table 1, Entry 4) with 1-azido-2-(2-(2methoxyethoxy)ethoxy)ethane (Scheme 2B) was studied. The complete disappearance of the alkyne band $\left(2120 \mathrm{~cm}^{-1}\right)$ in the Raman spectra of the modified sample ( $\mathrm{POC}_{0.77}-\mathrm{POC}-\mathrm{MEE}$, Fig. $5 B$ ) attests to the complete conversion of this reactive group into the corresponding 1,2,3-triazole. A $\mathrm{POC}_{0.34}-\mathrm{P}$-tB sample (Table 1, Entry 5) was finally reacted with an azide-fluorophore tag (Scheme 2C), with the aim to evidence the click modification by fluorescence microscopy. In order to exclude any adsorption of the fluorescein dye onto POC surface, a "control" experiment was first undertaken by exposing the alkyne POC to fluorophore, in the Huisgen cycloaddition reaction conditions but in absence of copper catalyst Fluorescence imaging of the control sample $\left(\mathrm{POC}_{0.34}\right.$-Control, Fig. 5C1) shows the absence of significant adsorption phenomena. On the contrary, when the reaction was performed in presence of the $\mathrm{Cu}$ catalyst, a fluorescence response is observed on the analysed surface, which guarantees the achievement of the click ligation with the fluorescent tag ( $\mathrm{POC}_{0.34}$-Fluo, Fig. $5 \mathrm{C} 2$ and Fig. S15 with the

A)

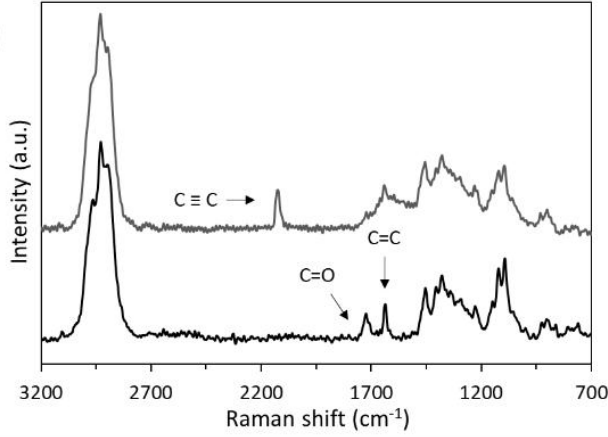

C1)

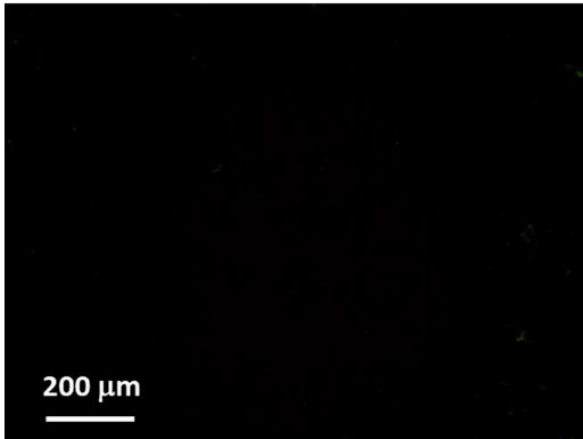

same samples analysed in reflection-mode). The general approach developed herein, based on the dual Passerini strategy bringing specific properties/functions and offering a potential post-modification step, allows for designing a panel of MFC objects exhibiting a structural versatility. This is achievable due to the choice of using periodate oxidized cellulose instead of TEMPO-oxidized cellulose substrates. From a more applicative point of view, the generation of such tailormade dually functionalized MFC substrates could potentially lead to the preparation of attractive functional cellulosic materials, whose properties can be suitably adjusted to the desired applications, as previously mentioned (e.g. fillers for nanocomposites, thickening or gel-forming agents, reinforcers for paper and paper boards....). ${ }^{13,14,20,48}$

\section{Conclusions}

The Passerini 3 component coupling was proved to be a simple and eco-friendly synthetic route to dually modify periodate oxidized microfibrillated celluloses with both carboxylic acid and isocyanide reactants added in one-pot conditions. The reaction, performed in heterogeneous aqueous medium in mild conditions, allowed for successfully generating two series of Passerini modified derivatives, bearing respectively three couples of functions: tert-butyl/alkyne, tert-butyl/alkene, and tert-butyl/methacrylate stemming from the coupling with the isocyanide and acid, respectively. The in-depth characterisation of the modified POC derivatives proved the generation of the desired products. The two used carboxylic acids as well as both POC possessing two different degree of

B)

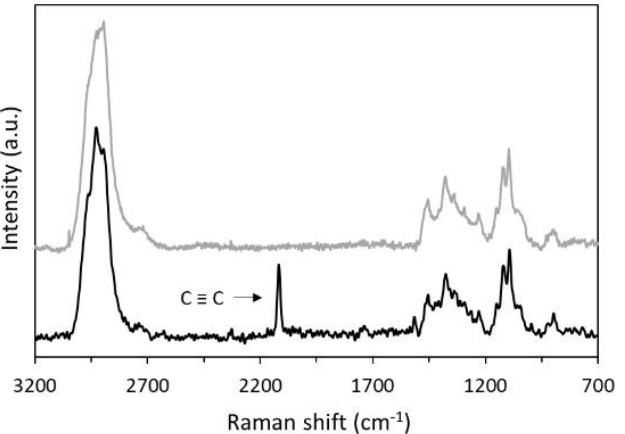

C2)

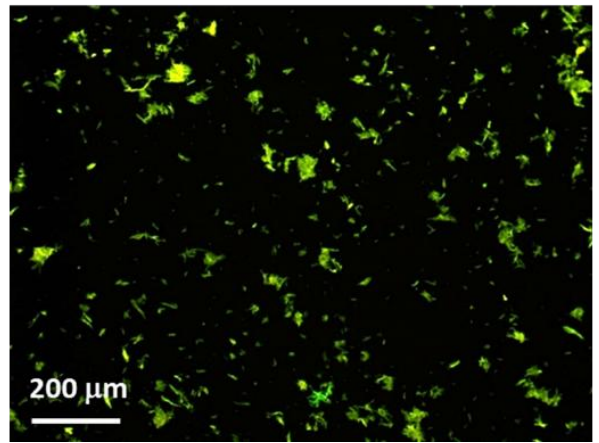

Fig. 5. A) Raman spectra of $P O C_{0.77}-\mathrm{MA}-t \mathrm{~B}$ (Table 1, Entry 11, POC $_{0.77}$-P-tB (Table 1, Entry 4, -) and of POC $0.77^{-P O C-M E E ~}$ ) and of $\mathrm{POC}_{0.77}$-Propargyl ( ); B) Raman spectra of and $\mathrm{C2}$ ) $\mathrm{POC}_{0.34}$-Fluo. 
oxidation were shown to exhibit similar Passerini reactivities. On the other hand, the increase of amount of acid and isocyanide reactants allows for promoting the Passerini efficiency and leads to a higher functionalization. Carboxylic acids used in the P-3CR were conveniently chosen in order to be prone to a post-modification step based on very popular striking synthetic coupling ligations. Indeed, the reactivity of POC bearing methacrylate functions in aza-Michael reaction step, as well as that of alkyne-functionalized products in copper catalysed Huisgen cycloaddition were revealed by IR, Raman spectroscopic and fluorescence microscopic characterisations. The structural versatility of the Passerini 3$\mathrm{CR}$, the availability of a large variety of commercial carboxylic acids, allowed by the use of periodate oxidized cellulose, and the reactivity of the dually modified MFC products in subsequent post-modification stages represent very attractive tools for the preparation of tailor-made functional MFC objects finding many potential applications in various fields. We strongly believe that this cascade synthetic approach (periodate oxidation, Passerini modification, post-modification by simple aqueous couplings) offers a powerful and sustainable alternative for the heterogeneous functionalisation of MFC substrates, without jeopardizing its unique attributes. Thus, this study can mobilise a large scientific community focusing on the development of biosourced materials by means of the use of emerging synthetic pathways.

\section{Experimental section}

\section{Materials}

A batch of paste-like never dried microfibrillated cellulose (MFC) prepared by a mechano-enzymatic treatment ${ }^{49,50}$ of spruce sulphite pulp, with a consistency of about $2 \%$, was purchased from the Centre Technique du Papier (CTP, Grenoble, France). Sodium metaperiodate with purity $\geq 99.8 \%$ was provided by Carl Roth (France). Methacrylic acid, 4pentynoic acid, tert-butyl isocyanide, propargylamine, 1-Azido2-(2-(2-methoxyethoxy) ethoxy)ethane, sodium ascorbate and anhydrous $\mathrm{CuSO}_{4}$ were supplied by Sigma Aldrich (France) and used without further purification. 5-Fluorescein-azide was obtained from Jena Bioscience (Germany).

\section{General procedure for periodate oxidation of MFC}

Periodate oxidized cellulose (POC) samples were prepared according to a previously reported protocol. ${ }^{29}$ In a typical experiment, about $250 \mathrm{~g}$ of the $2 \mathrm{wt}$. \% MFC suspension (equivalent to $5 \mathrm{~g}$ of dry cellulose) were inserted into a flask equipped with magnetic stirring. About $8.6 \mathrm{~g}$ sodium periodate, corresponding to a $\mathrm{NaIO}_{4} / \mathrm{AGU}$ molar ratio of 1.3 was dissolved in $200 \mathrm{~mL}$ deionized water and added to the MFC suspension. About $175 \mathrm{~mL}$ deionized water was further added to adjust the cellulose concentration to $7.9 \mathrm{~g} / \mathrm{L}$. The flask was wrapped with aluminium foils to avoid UV-light degradation of sodium metaperiodate. ${ }^{51}$ The oxidation was carried out for 3.6 or $9.7 \mathrm{~h}$ at room temperature to obtain POCs of two different DOs. At the end of the reaction, each mixture was centrifuged for $1 \mathrm{~h}$ at $20.000 \mathrm{~g}$. The pellet was then re-dispersed in deionized water using an Ultra-Turrax double cylinder homogenizer. The centrifugation/redispersion process was repeated 3 to 4 times to remove any residual salts until the conductivity of the supernatant was below $30 \mu \mathrm{S}$. The products were then concentrated to approximatively $0.5 \mathrm{wt}$. \% and stored at $4{ }^{\circ} \mathrm{C}$ before use. The obtained samples presented a degree of oxidation, defined as the average number of aldehyde groups introduced per AGU, of 0.34 (3.6 h oxidation time) and 0.77 (9.7 $\mathrm{h}$ oxidation time), respectively, as calculated by solid state ${ }^{13} \mathrm{C}$ CP-MAS NMR spectroscopy. ${ }^{29}$

\section{General procedure for the Passerini modification of POC}

POC suspensions ( $30 \mathrm{~g}, \approx 0.5$ wt. \%, 1 eq. of available $\mathrm{CHO}$ groups) were further concentrated to approximatively $1.5 \mathrm{wt}$. $\%$ by centrifugation (10 $\mathrm{min}, 4000 \mathrm{rpm}$ ) and removal of a known amount of supernatant. After $10 \mathrm{~min}$ of vigorous magnetic stirring, the desired carboxylic acid was added to the concentrated POC suspensions, followed by tert-butyl isocyanide. The amounts of carboxylic acid and isocyanide, with respect to the available $\mathrm{CHO}$ functions, were varied to adjust the extent of the POC modification, as indicated in Table 1. The mixture was stirred for $18 \mathrm{~h}$ and, at the end of the reaction, $30 \mathrm{~mL}$ of water were added and the mixture was centrifuged (10 $\mathrm{min}, 4000 \mathrm{rpm}$ ). After removal of the supernatant, modified POC were re-dispersed in $30 \mathrm{~mL}$ of water by vigorous magnetic stirring for $20 \mathrm{~min}$. The centrifugation/redispersion process was repeated 5 times, to remove any unreacted reagents. Centrifugated POC were finally freeze-dried, leading to the desired Passerini products. The mass yield was calculated by dividing the mass of the product, recovered after work-up, by the maximum mass of the product theoretically achievable:

$$
\text { Mass yield }(\%)=\frac{\text { Recovered amount of product }}{\text { Theoretical amount of product }} \times 100
$$

Blank reactions were also performed to exclude any adsorption of the reagents on POC. In this case, POC and the desired carboxylic acid were subjected to the reaction and work-up protocol, without addition of tert-butyl isocyanide.

\section{Aza-Michael addition protocol}

Methacrylate functionalized POC, $\left(\mathrm{POC}_{0.77}-\mathrm{M}-\mathrm{t} \mathrm{B}, \mathrm{DS}=0.11,6\right.$ $\mathrm{mg}, 3.7 \times 10^{-3} \mathrm{mmol}$ of methacrylate functions, 1 eq.) was suspended in $0.2 \mathrm{~mL}$ of water by magnetic stirring, for $1 \mathrm{~h}$. Propargylamine ( $3 \mu \mathrm{L}, 0.048 \mathrm{mmol}, 14$ eq.) was added and the reaction was left to proceed for $6 \mathrm{~h}$, at RT. At the end of the reaction, $12 \mathrm{~mL}$ of water were added and the mixture was centrifuged (10 min, $4000 \mathrm{rpm})$. After removal of the supernatant, the aza-Michael product was re-dispersed in 12 $\mathrm{mL}$ of water by vigorous magnetic stirring for $20 \mathrm{~min}$. The centrifugation/redispersion process was repeated 5 times, to remove any unreacted reagents, followed by freeze-drying.

\section{Azide-alkyne Huisgen cycloaddition (CuAAc) protocol}

Reaction between alkyne functionalized POC and 1-Azido-2-(2-(2methoxyethoxy)ethoxy)ethane. Alkyne-functionalized POC, $\left(\mathrm{POC}_{0.77}-\mathrm{P}-\mathrm{tB}, \mathrm{DS}=0.1,25 \mathrm{mg}, 0.017 \mathrm{mmol}\right.$ of alkyne functions, 
1 eq.) was suspended in $1.7 \mathrm{~mL}$ of water by magnetic stirring, for $1 \mathrm{~h}$. A 9 wt. \% aqueous sodium ascorbate solution $(49 \mathrm{mg}$ $0.25 \mathrm{mmol}, 15$ eq.) was added to the mixture and the vial was protected from light with aluminium foil. 1-Azido-2-(2-(2methoxyethoxy)ethoxy)ethane ( $56 \mu \mathrm{L}, 0.32 \mathrm{mmol}, 19$ eq.) was introduced drop by drop in the vial and the reaction was triggered by incorporating a 0.3 wt. \% aqueous copper sulphate solution ( $2 \mathrm{mg}, 0.013 \mathrm{mmol}, 0.7$ eq.). After $40 \mathrm{~h}$ of reaction at ambient temperature, $30 \mathrm{~mL}$ of water were added and the mixture was centrifuged (10 min, $4000 \mathrm{rpm}$ ). After removal of the supernatant, Huisgen product was re-dispersed in $30 \mathrm{~mL}$ of water by vigorous magnetic stirring for $20 \mathrm{~min}$. The centrifugation/redispersion process was repeated 5 times, to remove any unreacted reagents, followed by freeze-drying.

Reaction between alkyne functionalized $P O C$ and 5-Fluoresceinazide. Alkyne-functionalized POC, $\left(\mathrm{POC}_{0.34} \mathrm{P}-\mathrm{t} \mathrm{B}, \mathrm{DS}=0.04,3.6 \mathrm{mg}\right.$, $8.5 * 10^{-4} \mathrm{mmol}$ of alkyne functions, 1 eq.) was suspended in $0.5 \mathrm{~mL}$ of water by magnetic stirring, for $1 \mathrm{~h}$. A $5 \mathrm{wt}$. \% aqueous sodium ascorbate solution ( $4 \mathrm{mg}, 0.02 \mathrm{mmol}, 23.5$ eq.) was added to the mixture and the vial was protected from light with aluminium foil. 5-Fluorescein-azide (5 mg, $0.01 \mathrm{mmol}, 13 \mathrm{eq}$ ) ) was dissolved in 0.7 $\mathrm{mL}$ of DMSO and introduced drop by drop in the vial. The reaction was triggered by incorporating a $0.2 \mathrm{wt}$. \% aqueous copper sulphate solution ( $0.2 \mathrm{mg}, 1.3 * 10^{-3} \mathrm{mmol}, 1.5 \mathrm{eq}$.) and left to proceed at RT for $40 \mathrm{~h}$. At the end of the reaction, $2 \mathrm{~mL}$ of DMSO were added and the mixture was centrifuged ( $10 \mathrm{~min}, 4000 \mathrm{rpm}$ ). After removal of the supernatant, the CuAAc modified product was re-dispersed in 2 $\mathrm{mL}$ of DMSO by vigorous magnetic stirring for $10 \mathrm{~min}$. The centrifugation/ redispersion process was repeated 5 times in DMSO and 5 in water, to remove any unreacted reagents. The sample was concentrated to approximatively $0.9 \mathrm{wt}$. \% by centrifugation (10 min, $4000 \mathrm{rpm}$ ) and stored at $4{ }^{\circ} \mathrm{C}$ before microscopy. A control sample was also prepared to exclude any adsorption of the fluorophore on POC. In this case, alkyne functionalized POC and 5Fluorescein-azide were subjected to the reaction and work-up protocol, without addition of the copper catalyst.

\section{Characterizations}

\section{Scanning electron microscopy (SEM).}

Pristine or derivatized MFC films obtained by casting were first coated with 2-3 nm Au/Pd using a Baltec MED 020 apparatus. Secondary electron images of the specimens were recorded with a FEI Quanta 250 scanning electron microscope (SEM) equipped with a field emission gun and operated at $2 \mathrm{kV}$.

Thermogravimetric analysis (TGA). TGA measurements were performed on 10-15 mg of sample, using a TA Instruments TGA Q500 apparatus at a heating rate of $10^{\circ} \mathrm{C} / \mathrm{min}$, up to $580{ }^{\circ} \mathrm{C}$, under nitrogen $(90 \mathrm{~mL} / \mathrm{min}) . \mathrm{Td}_{\text {onset }}$ and $\mathrm{Td}_{\max }$ stand for the temperature corresponding to the onset of the degradation and to the maximum to the derived curve, respectively.

Infrared analysis (IR). FT-IR spectra were recorded with a Nicolet iS10 (ThermoFisher Scientific) by using attenuated total reflectance (Smart iTR Diamond) ATR and collecting 32 scans from 700 to $4000 \mathrm{~cm}^{-1}$.
Raman analysis. Raman spectroscopy was carried out using a DXR Raman Microscope (ThermoFisher Scientific) equipped with an excitation wavelength at $532 \mathrm{~nm}$ and a $10 \mathrm{~mW}$ beam power. The spectra were collected using a $50 \mu \mathrm{m}$ pinhole aperture and a polynomial fitting (at a polynomial order of 4) was applied for fluorescence background correction. The 1300 x $800 \mu \mathrm{m}$ Raman micrographs were generated from spectral data using point-by-point scanning with a $100 \mu \mathrm{m}$ step size.

${ }^{13}$ C CP-MAS Nuclear Magnetic Resonance (NMR). Solid-state ${ }^{13} \mathrm{C}$ NMR spectra were recorded using a Bruker AVANCE III NMR spectrometer operating at $125.73 \mathrm{MHz}$, using the CrossPolarization Magic-Angle-Spinning (CP-MAS) method. A $4 \mathrm{~mm}$ triple resonance probe was employed and the spinning speed was set at $12 \mathrm{kHz}$. At least 1500 scans were integrated with a contact time of $2 \mathrm{~ms}$ and a repetition time of $5 \mathrm{~s}$. The ${ }^{1} \mathrm{H}$ radiofrequency field strength was set to give a $90^{\circ}$ pulse duration of $2.5 \mu \mathrm{s}$. The chemical shifts were calibrated with respect to the $\mathrm{CH}$ peak of adamantane (28.5 ppm). The DS, defined as the average number of alkyne or methacrylate functions grafted per AGU (DS value comprised between 0 and DO), was measured by ${ }^{13} \mathrm{C} C P-M A S N M R$. It was calculated from the ratio between the integration values of the signals specific to the grafted moieties $\left(I_{\text {graft }}\right)$ and those specific to the POC backbone $\left(I_{\text {Poc }}\right)$, by taking into account the number of carbons responsible for the integrated areas $\left(\mathrm{C}_{\text {graft }}\right.$ and $\mathrm{C}_{\mathrm{POC}}$, respectively):

$$
D S=\frac{I_{\text {graft }} / C_{\text {graft }}}{I_{P O C} / C_{P O C}}
$$

When 4-pentynoic acid was employed (Figure 5B), the contribution of carbons 13 and 14 , overlapping the $P O C$ signals, was considered for the calculation of I $I_{\text {Poc. }}$. The DS, was calculated as an average value from the integrals of signals 712. When methacrylic acid was used (Figure 5C), DS was obtained as an average value from the integrals of signals 7-10 and 13.

Fluorescence microscopy. Fluorescence microscope images were obtained on a Zeiss Axio Scope.A1 fluorescence light microscope (Carl Zeiss Microimaging, NY) with a $10 \times$ objective and $450-490 \mathrm{~nm}$ excitation wavelength. The emission signal was collected between 505 and $530 \mathrm{~nm}$. One drop of the dispersion ( $\approx 0.9 \mathrm{wt}$. \% of $\mathrm{POC}_{0.34}$-Fluo in water) was placed on a glass slide and left to dry for a couple of hours, before microscopy. To take adsorption phenomena into account, analysis of a control sample (alkyne-functionalized POC treated in azide-alkyne Huisgen cycloaddition conditions without addition of copper catalyst) was also carried out.

\section{Conflicts of interest}

Authors declare that there is no conflict of interest 


\section{Acknowledgements}

This work was supported by the Agence Nationale de la Recherche (ANR) in France as part of the project PLACELMAT (Grant number: ANR-14-CE07-0018-03). The authors acknowledge support from Nanobio-ICMG FR 2607 for access to the electron microscopy and NMR platforms. The authors are grateful to Chantal Lorentz for her support for the ${ }^{13} \mathrm{C}$ CP-MAS data acquisition, to Christine LancelonPin (CERMAV, Grenoble) for performing the SEM analyses and to Laura Courty for her precious advices in Raman experiments.

\section{References}

1 H. G. O. Alvim, E. N. Da Silva Júnior and B. A. D. Neto, RSC Adv., 2014, 4, 54282-54299.

2 M. Passerini and L. Simone, Gazz. Chim. Ital., 1921, 51, 126-129.

3 M. C. Pirrung and K. D. Sarma, J. Am. Chem. Soc., 2003, 126, 444-445.

$4 \quad$ L. Banfi and R. Riva, in In Organic Reactions, John Wiley \& Sons, 2005.

5 A. Llevot, A. C. Boukis, S. Oelmann, K. Wetzel and M. A. R. Meier, Top. Curr. Chem., 2017, 375, 1-29.

6 R. Kakuchi, Angew. Chem. Int. Ed. Engl., 2014, 53, 46-48.

7 R. Afshari and A. Shaabani, ACS Comb. Sci., 2018, 20, 499528.

8 A. E. J. De Nooy, G. Masci and V. Crescenzi, Macromolecules, 1999, 32, 1318-1320. A. E. J. De Nooy, D. Capitani, G. Masci and V. Crescenzi, Biomacromolecules, 2000, 1, 259-267.

10 S. Perez and D. Samain, Adv. Carbohydr. Chem. Biochem., 2010, 64, 25-116.

11 D. Klemm, F. Kramer, S. Moritz, T. Lindström, M. Ankerfors, D. Gray and A. Dorris, Angew. Chemie - Int. Ed., 2011, 50, 5438-5466.

12 I. Siró and D. Plackett, Cellulose, 2010, 17, 459-494.

13 H. Charreau, M. L. Foresti and A. Vazquez, Recent Pat. Nanotechnol., 2012, 7, 56-80.

14 R. J. Moon, A. Martini, J. Nairn, J. Simonsen and J. Youngblood, Chem. Soc. Rev., 2011, 40, 3941-3994.

15 A. Pettignano, A. Charlot and E. Fleury, Polym. Rev., 2019, 59, 510-560.

16 B. Thomas, M. C. Raj, B. K. Athira, H. M. Rubiyah, J. Joy, A. Moores, G. L. Drisko and C. Sanchez, Chem. Rev., 2018, 118, 11575-11625.

D. Klemm, E. D. Cranston, D. Fischer, M. Gama, S. A. Kedzior, D. Kralisch, F. Kramer, T. Kondo, T. Lindström, S. Nietzsche, K. Petzold-Welcke and F. Rauchfuß, Mater. Today, 2018, 21, 720-748.

18 A. Pettignano, A. Daunay, C. Moreau, B. Cathala, A. Charlot and E. Fleury, ACS Sustain. Chem. Eng., 2019, 7, 1468514696.

19 Z. Söyler, K. N. Onwukamike, S. Grelier, E. Grau, H. Cramail and M. A. R. Meier, Green Chem., 2018, 20, 214-224.

20 N. Lavoine, I. Desloges, A. Dufresne and J. Bras, Carbohydr. Polym., 2012, 90, 735-764.

applications: a guide for end users, TAPPI Press, 2017.

22
J. Miller, Nanocellulose: technology, applications, and markets. RISI, 2014; updated Market-Intell, 2017. Y. Y. Khine, S. Ganda and M. H. Stenzel, ACS Macro Lett., 2018, 7, 412-418.

P. A. Larsson, L. A. Berglund and L. Wågberg, Cellulose, 2014, 21, 323-333.

P. A. Larsson, L. A. Berglund and L. Wågberg, Biomacromolecules, 2014, 15, 2218-2223.

V. López Durán, P. A. Larsson and L. Wågberg, Carbohydr. Polym., 2018, 182, 1-7.

E. L. Jackson and C. S. Hudson, J. Am. Chem. Soc., 1937, 59, 2049-2050.

E. L. Jackson and C. S. Hudson, J. Am. Chem. Soc., 1938, 60, 989-991.

J. Leguy, Y. Nishiyama, B. Jean and L. Heux, ACS Sustain. Chem. Eng., 2019, 7, 412-420.

S. Arndt, D. Weis, K. Donsbach and S. R. Waldvogel, Angew. Chemie - Int. Ed., 2020, 59, 8036-8041.

S. Koprivica, M. Siller, T. Hosoya, W. Roggenstein, T. Rosenau and A. Potthast, ChemSusChem, 2016, 9, 825833.

X. Dang, P. Liu, M. Yang, H. Deng, Z. Shan and W. Zhen, Cellulose, 2019, 26, 9503-9515.

U. J. Kim and S. Kuga, Thermochim. Acta, 2001, 369, 79-85. Z. Sabzalian, M. N. Alam and T. G. M. van de Ven, Cellulose, 2014, 21, 1381-1393.

L. Jin, W. Li, Q. Xu and Q. Sun, Cellulose, 2015, 22, 24432456.

J. A. Sirviö, M. Visanko, O. Laitinen, A. Ämmälä and H. Liimatainen, Carbohydr. Polym., 2016, 136, 581-587. F. Azzam, M. Galliot, J. L. Putaux, L. Heux and B. Jean, Cellulose, 2015, 22, 3701-3714.

N. Guigo, K. Mazeau, J. L. Putaux and L. Heux, Cellulose, 2014, 21, 4119-4133.

J. A. Sirviö, A. Kolehmainen, M. Visanko, H. Liimatainen, J. Niinimäki and O. E. O. Hormi, ACS Appl. Mater. Interfaces, 2014, 6, 14384-14390.

J. A. Sirviö, T. Hasa, J. Ahola, H. Liimatainen, J. Niinimäki and O. Hormi, Phosphonated nanocelluloses from sequential oxidative-reductive treatment - Physicochemical characteristics and thermal properties, 2015, vol. 133. J. Lebeau, J. P. Efromson and M. D. Lynch, Front. Bioeng. Biotechnol., 2020, 8, 207. U.S. Patent, US8362296B2, 2013.

Q. X. Hou, W. Liu, Z. H. Liu and L. L. Bai, Ind. Eng. Chem. Res., 2007, 46, 7830-7837.

Q. G. Fan, D. M. Lewis and K. N. Tapley, J. Appl. Polym. Sci., 2001, 82, 1195-1202.

P. Larkin, Infrared and Raman spectroscopy: principles and spectral interpretation, Elsevier, 2017.

A. Codou, N. Guigo, L. Heux and N. Sbirrazzuoli, Compos. Sci. Technol., 2015, 117, 54-61.

H. Yang, D. Chen and T. G. M. van de Ven, Cellulose, 2015, 22, 1743-1752.

T. Lindström, C. Aulin, A. Naderi and M. Ankerfors, Encycl. Polym. Sci. Technol., 2014, 1-34. 
Journal Name

49

L. Falcoz-Vigne, Y. Ogawa, S. Molina-Boisseau, Y. Nishiyama, V. Meyer, M. Petit-Conil, K. Mazeau and L. Heux, Cellulose, 2017, 24, 3725-3739.

50 M. Pääkko, M. Ankerfors, H. Kosonen, A. Nykänen, S. Ahola, M. Österberg, J. Ruokolainen, J. Laine, P. T. Larsson, O. Ikkala and T. Lindström, Biomacromolecules, 2007, 8, 1934-1941.

51 M. C. R. Symons, J. Chem. Soc., 1955, 2794-2796. 